\title{
Angioplasty, Stenting and Other Potential Treatments of Atherosclerotic Stenosis of the Intracranial Arteries: Past, Present and Future
}

\author{
Ashley Wabnitz, Marc Chimowitz \\ Department of Neurology, Medical University of South Carolina, Charleston, SC, USA
}

\begin{abstract}
Although there is an intuitive appeal to treat symptomatic stenotic intracranial arteries with endovascular therapies such as angioplasty and stenting, current data from randomized trials show intensive medical therapy is far superior for preventing stroke. This is in large part due to the high risk of peri-procedural stroke from angioplasty and stenting. If angioplasty and stenting is to emerge as a proven treatment for intracranial stenosis, endovascular techniques will need to become much safer, identification of patients with intracranial stenosis who are at particularly high risk of stroke despite intensive medical therapy will need to be targeted, and well-designed randomized trials will be necessary to show endovascular therapy is superior to medical therapy in these high-risk patients.
\end{abstract}

Keywords Intracranial atherosclerosis; Angioplasty; Stenting

\author{
Correspondence: Marc Chimowitz \\ Department of Neurology, Medical \\ University of South Carolina, 19 \\ Hagood Avenue, Suite 501, \\ Charleston, SC 29425, USA \\ Tel: +1-843-792-3020 \\ Fax: +1-843-792-2484 \\ E-mail:mchimow@musc.edu \\ Received: August 15, 2017 \\ Revised: September 20, 2017 \\ Accepted: September 20, 2017 \\ The authors have no financial conflicts \\ of interest.
}

\section{Introduction}

Atherosclerotic stenosis of the intracranial arteries (ICAS) is one of the most common causes of stroke worldwide and is associated with a high risk of recurrent stroke despite medical management. ${ }^{1,2}$ Patients who are at particularly high risk for recurrent stroke are those with severe stenosis (70-99\% luminal narrowing) and recent symptoms. ${ }^{3}$ This has led to the exploration of percutaneous transluminal angioplasty and stenting (PTAS) techniques to lower the risk of stroke in these patients.

\section{Past: history of stenting and angioplasty for ICAS}

Intracranial angioplasty alone was initially pursued as a treatment option for ICAS in the 1980s but was associated with a high risk of stroke or death, leading to the procedure falling out of favor. ${ }^{4}$ Renewed interest in using PTAS for intracranial stenosis followed endovascular technological advances and the growing success with coronary angioplasty/stenting procedures. This resurgence of interest led to a number of studies evaluating PTAS for patients with ICAS.

Retrospective studies using angioplasty alone showed that technical success (reduction of stenosis to $<50 \%$ ) could be achieved in over $80 \%$ of patients but the rate of stroke or death within 30 days of angioplasty varied between $4 \%$ and $40 \%$, and re-stenosis rates were $24-40 \% .^{5-10}$ Additionally angioplasty alone can be associated with immediate elastic recoil of the artery, dissection, acute vessel closure, and residual stenosis $>50 \%$ following the procedure. These limitations, coupled with the success of stenting in the coronary circulation, led to the emergence of stenting as the preferred endovascular technique for treating ICAS.

Initial single-center retrospective intracranial stenting studies showed promising results with balloon-mounted coronary 
stents used off-label suggesting stenting could be performed safely with high technical success rates. ${ }^{11-13}$ These results were supported by initial industry sponsored prospective phase I trials utilizing stents approved specifically for intracranial use. The Stenting of Symptomatic Atherosclerotic Lesions in the Vertebral or Intracranial Arteries (SSYLVIA) trial was a nonrandomized trial using the NEUROLINK stent in 61 patients with symptomatic (50-99\%) intracranial stenosis or extra-cranial vertebral artery stenosis. ${ }^{14}$ The 30 -day rate of death or stroke was $6.6 \%$ and the 1-year stroke rate was $10.9 \%$. However, restenosis ( $>50 \%$ luminal narrowing) occurred in $32 \%$ of patients. The Wingspan stent system was evaluated in a small European and Asian single arm trial consisting of 45 patients undergoing treatment of medically refractory patients with symptomatic ICAS of $50-99 \%{ }^{15}$ In this trial, the 30 -day rate of death or stroke was $4.5 \%$, the 6 -month rate of ipsilateral stroke or death was 7\%, and restenosis at six months was 7.5\%. The latter device was approved by the Food and Drug Administration under a humanitarian device exemption (HDE) and used in practice in the USA for patients with $50-99 \%$ stenosis who were refractory to medical management. This allowed more data to be collected in two USA registries on the outcome of ICAS patients treated under the HDE.

The NIH Wingspan stent registry showed that the risk of any stroke or death within 30 days or any stroke in territory from 30 days to 6 months was $14 \% .{ }^{16}$ A post-hoc analysis of the NIH Wingspan registry found that factors associated with increased risk of stroke in the territory were: posterior circulation stenosis, treatment at low volume sites, stenting soon after a qualifying event, or stroke as opposed to transient ischemic attack (TIA) as the event leading to stenting. ${ }^{17}$ In the US Multicenter registry, 81 of 82 lesions (98.8\%) were successfully stented during the first treatment session. ${ }^{18}$ Of the 82 lesions treated, there were $5(6.1 \%)$ major periprocedural neurological complications, 4 of which ultimately led to death within 30 days of the procedure.

While these registries were helpful in establishing the potential safety of the Wingspan stent in medically refractory patients, the lack of medically treated controls prevented any conclusion regarding the potential efficacy of stenting. However, these studies and the poor outcome of patients with 7099\% stenosis and TIA or stroke within the previous 30 days who were treated medically in the Warfarin Aspirin Symptomatic Intracranial Disease (WASID) trial set the foundation for future randomized control trials to compare medical management versus PTAS.

\section{Present: recent studies evaluating PTAS for ICAS}

There have been two major randomized controlled trials evaluating outcomes related to intracranial angioplasty and stenting versus medical management-The Stenting Versus Aggressive Medical Management Therapy for Intracranial Arterial Stenosis (SAMMPRIS) trial and the Vitesse Intracranial Stent Study for Ischemic Stroke Therapy (VISSIT) trial. SAMMPRIS was funded by the National Institutes of Health and performed at 50 sites in the United States ${ }^{19}$ while VISSIT was industry-funded and conducted at sites in the USA, China, and Europe. ${ }^{20}$ Both trials included patients with TIA or stroke within 30 days prior to enrollment that was attributed to severe (70-99\%) intracranial stenosis. Both included similar medical management arms, however they differed in the device offered for endovascular treatment. SAMMPRIS trial used the self-expanding Wingspan stent whereas VISSIT used the balloon-mounted VITESSE stent. In brief, the medical management utilized across trials was dual antiplatelet therapy with aspirin 81-325 $\mathrm{mg}$ daily as well as clopidogrel $75 \mathrm{mg}$ for the first 90 days, followed by monotherapy with aspirin only for the duration of the study. Blood pressure targets were set at systolic blood pressure of less than $140 \mathrm{~mm} \mathrm{Hg}$ (<130 mm Hg for diabetic patients in SAMMPRIS) and low-density lipoprotein cholesterol targets of $<70 \mathrm{mg} / \mathrm{dL}$ in SAMMPRIS and $<100 \mathrm{mg} / \mathrm{dL}$ in VISSIT. ${ }^{20,21}$ Additionally, SAMMPRIS included a lifestyle modification program focusing on smoking cessation, weight management, and exercise counseling.

Both SAMMPRIS and VISSIT were stopped early due to higher than expected peri-procedural risk in the stenting groups and much lower than expected rates of stroke in the medical management group. For SAMMPRIS, the absolute risk reduction for stroke from medical therapy alone was $8.9 \%$ at 30 days and $9.0 \%$ at 3 years. ${ }^{19,22}$ The data from VISSIT showed an even worse outcome from stenting with an absolute increase in the rate of ischemic stroke in the territory from stenting of $25.1 \%$ at one year, and the absolute risk of ischemic and hemorrhagic stroke from stenting at one year of 33.7\%. The latter equates to a number needed to harm from stenting of only three patients at 1 year. ${ }^{20}$ While the poor outcome from stenting was driven by the high 30-day stroke rates in both trials (10.3\% ischemic strokes and 4.5\% hemorrhagic strokes in SAMMPRIS; $17.2 \%$ ischemic stroke and $8.6 \%$ hemorrhagic stroke in VISSIT), the longer-term outcomes in both trials failed to show any benefit from stenting beyond the peri-procedural period. ${ }^{19,20,22}$ Further, a SAMMPRIS post-hoc analysis failed to show any subgroup of patients with ICAS who significantly 
benefited from stenting, even those at particularly high risk of stroke on aggressive medical therapy. ${ }^{23}$

Of note, the above peri-procedural risks are higher than those shown in stenting registries. ${ }^{16,24}$ Randomized clinical trials rely on rigorous evaluation of all potential endpoints by site monitoring and blinded adjudicators while these protocols are often not required for registry data which is likely to lead to underestimation of recurrent stroke rates.

More recently, the Chinese stenting registry was established as the first multicenter, prospective, endovascular registry for symptomatic ICAS in China enrolling 300 patients. ${ }^{25}$ This study had more rigorous patient selection criteria than the previously described registries including parameters on lesion length and target vessel diameter and requirement that lesions be attributable to hypoperfusion in the territory of the culprit artery. Neurointerventionialists were given more freedom in choosing the device used for the procedure with options of a balloonmounted stent or balloon predilation with self-expanding stent deployment based on patient characteristics and operator preference. Further, there was typically a delay in the stenting procedure for a recommended time of at least 3 weeks after the last event prior to the procedure. Similar medical management to SAMMPRIS was used in this registry with dual antiplatelet for 90 days plus similar targets for systolic blood pressure ( $<130 \mathrm{~mm} \mathrm{Hg}$ for diabetic patients and $<140 \mathrm{~mm} \mathrm{Hg}$ for all others), low-density lipoprotein targets of $<70 \mathrm{mg} / \mathrm{dL}$, and lifestyle modification including smoking cessation, and counseling for obesity and sedentary lifestyles. For the Chinese registry the primary outcome of any stroke, TIA, or death within 30 days was $4.3 \%,{ }^{25}$ which is within the confidence interval $(5.8 \%$ [3.4-9.7]) for the primary endpoint at 30 days in the medical management only arm of SAMMPRIS. ${ }^{19}$

There are several factors that could influence the better outcomes of stented subjects in the Chinese registry compared with the SAMMPRIS and VISSIT trials. The incidence of intracranial atherosclerosis is more common in the Chinese population than in whites, ${ }^{26}$ which could have theoretical benefit on the experience level of Chinese interventionists. However, the argument that lack of experienced endovascular interventionists in SAMMPRIS and VISSIT explains the high peri-procedural risk in those trials lacks merit when considering the interventionists who participated in these trials went through a credentialing process and most were the same interventionists who had participated in the prior stenting registries reporting lower peri-procedural stroke rates. ${ }^{21}$ Further, the most experienced interventionists in SAMMPRIS did not have lower stroke rates and there was also no difference in outcome between the highest and lowest enrolling sites in SAMMPRIS or in subjects stented early versus late in the trial when more experience would have accumulated. ${ }^{27}$ Additionally, the VISSIT trial had sites in Europe and China with higher reported peri-procedural events than in SAMMPRIS. ${ }^{20}$

Other potential reasons for the improved outcomes in the Chinese registry could be the younger patient population ${ }^{28}$ and patients presenting more often with TIAs rather than stroke (presenting with stroke has been shown to be associated with a higher risk of a stroke after stenting and in medically treated patients). ${ }^{29,30}$ Unstable patients, defined as fluctuating or progressive symptoms within 2 days of undergoing stenting, have been shown to have significantly higher risk of adverse outcomes such as stroke in the territory of the stenotic vessel after stent placement ( $25.9 \%$ vs. $4.1 \%$ in stable patients, $P=0.004){ }^{31}$ As such, the time delay between qualifying event and intervention in the Chinese registry may have allowed for the plaque to stabilize and thereby lower the risk of the procedure. Lastly, the careful selection of patients in the Chinese registry likely led to a much lower stroke rate than in other endovascular studies and trials. Nevertheless, the Chinese stenting registry data are encouraging and will hopefully lead to a randomized trial in China to compare the outcome of PTAS versus medical management in high-risk patients with ICAS.

\section{Future directions for PTAS and other novel treatments of ICAS}

\section{Advancement in PTAS techniques}

Most of the peri-procedural strokes in SAMMPRIS were perforator infarcts felt to be from "snow-plowing" effect (pushing the atherosclerotic plaque into perforator vessels during either the balloon dilation or the stent placement) or reperfusion hemorrhage. ${ }^{18,32}$ While "snow-plowing" effect is likely to remain with any intervention, even angioplasty alone, the potential of new technology or modified endovascular procedures to mitigate these events may allow for improved outcomes of endovascular therapy. ${ }^{33}$ Additionally, careful patient selection to avoid those with perforator infarcts on initial presentation, such as selected for in the more recent Asian studies, can further reduce this complication.

Advancements in intracranial stenting will include the further technical advancement of the devices utilized. In the cardiac population, drug-eluting stents (DES) have been shown to be effective at reducing the rate of restenosis compared to bare metal stents. Restenosis is also a common problem in the intracranial stenting population with incidence as high as $30 \%{ }^{34}$ There have been limited studies evaluating DES in the intracranial population. Park et al. ${ }^{35}$ analyzed a small series of 
11 patients who underwent intracranial DES placement. They found only 1 patient had restenosis of the 9 who completed imaging follow-up, but this had resolved at subsequent followup after change in antiplatelet regimen. Other shorter duration studies showed favorable clinical outcomes with the use of intracranial DES, ${ }_{1}^{36-38}$ however larger trials supporting their benefit over current practice are still lacking. Other advancements such as bioresorbable stents and biological stents are emerging in the cardiac literature and will be exciting to watch for potential benefit in the intracranial stenosis population. These have the potential at reducing complications such as neoatherosclerosis and restenosis thereby improving long-term outcomes of intracranial stenting.

\section{Focus on patients whose symptoms are caused by hypoperfusion}

Future randomized clinical trials should consider selection of patients demonstrating hemodynamic compromise as the mechanism of their stroke related to ICAS. Based on an analysis of infarct patterns in the WASID trial hypoperfusion results in roughly $8.8 \%$ of the stroke in this population. ${ }^{39}$ Patients with poor collateral flow, leading to hypoperfusion-related infarcts, are highly likely to fail medical therapy. ${ }^{40,41}$ In the Vertebrobasilar Flow Evaluation and Risk of Transient Ischemic Attack and Stroke (VERTTAS) study of subjects with vertebrobasilar stenosis, impaired blood flow distal to the stenosis was also a strong predictor of recurrent stroke..$^{42}$ These findings all support the importance of hemodynamic factors such as impaired distal blood flow and poor collaterals in the pathophysiology of stroke in ICAS patients.

Currently a randomized controlled trial is underway in China to compare medical therapy with medical therapy plus intervention in patients with severe symptomatic ICAS and hypoperfusion symptoms. ${ }^{43}$ Trials like this are important in understanding the effectiveness and safety of current PTAS procedures compared to medical management alone, particularly in the most vulnerable ICAS patients.

\section{Novel non-endovascular therapy}

Lastly, a novel non-endovascular treatment, remote limb ischemic conditioning (RLIC), has emerged as a potential treatment for ICAS. RLIC involves producing repetitive, transient non-injurious ischemia of a limb by inflating a blood pressure cuff with the intention of protecting the brain from subsequent ischemia. Pre-clinical studies suggest that RLIC increases cerebral blood flow, most likely by releasing nitrite into the circulation. ${ }^{44,45}$ RLIC demonstrated efficacy compared to usual medical management in two small randomized trials of ICAS patients in China. ${ }^{46,47}$ The first trial randomized 68 adults with TIA or stroke due to 50-99\% ICAS to bilateral upper extremity conditioning twice daily for 300 days or standard medical management. In the RLIC group there was a marked reduction in the incidence of recurrent strokes at both 90 days (5\% vs. 23.3\%) and 300 days ( $7.9 \%$ vs. $26.7 \%)$, and increased cerebral blood flow as measured by SPECT and transcranial Doppler compared with the control group. ${ }^{46}$ The second trial randomized 58 subjects aged 80-95 with more severe symptomatic stenosis measuring $70-99 \%$ to either bilateral upper extremity RLIC twice daily or sham RLIC twice daily for 180 days, both groups receiving standard medical management. The RLIC group had fewer strokes and TIAs compared to the sham RLIC group at 180 days ( 9 events vs. 19 events, $P<0.05$ ). ${ }^{47}$ Larger Phase III trials are needed to better evaluate the utility of RLIC as an adjunct in preventing stroke in patients with ICAS.

\section{Summary}

PTAS has yet to be shown to be safe and more effective than medical management for the treatment of ICAS. While more recent non-randomized studies have suggested that PTAS is safe and has a potential therapeutic role in well-selected highrisk patients who have a poor outcome on medical treatment, PTAS will only emerge as the standard of care for these patients if shown to be superior to medical management in randomized trials.

\section{References}

1. Chimowitz MI, Lynn MJ, Howlett-Smith H, Stern BJ, Hertzberg VS, Frankel MR, et al. Comparison of warfarin and aspirin for symptomatic intracranial arterial stenosis. $N$ Engl J Med 2005;352:1305-1316.

2. Kwon SU, Hong KS, Kang DW, Park JM, Lee JH, Cho YJ, et al. Efficacy and safety of combination antiplatelet therapies in patients with symptomatic intracranial atherosclerotic stenosis. Stroke 2011;42:2883-2890.

3. Kasner SE, Chimowitz MI, Lynn MJ, Howlett-Smith H, Stern $B J$, Hertzberg VS, et al. Predictors of ischemic stroke in the territory of a symptomatic intracranial arterial stenosis. Circulation 2006;113:555-563.

4. Sundt TM Jr, Smith HC, Campbell JK, Vlietstra RE, Cucchiara RF, Stanson AW. Transluminal angioplasty for basilar artery stenosis. Mayo Clin Proc 1980;55:673-680.

5. Higashida RT, Tsai FY, Halbach W, Dowd CF, Smith T, Fraser $\mathrm{K}$, et al. Transluminal angioplasty for atherosclerotic disease of the vertebral and basilar arteries. J Neurosurg 1993;78: 
192-198.

6. Clark WM, Barnwell SL, Nesbit G, O'Neill OR, Wynn ML, Coull BM. Safety and efficacy of percutaneous transluminal angioplasty for intracranial atherosclerotic stenosis. Stroke 1995; 26:1200-1204.

7. Connors JJ 3rd, Wojak JC. Percutaneous transluminal angioplasty for intracranial atherosclerotic lesions: evolution of technique and short-term results. J Neurosurg 1999;91:415423.

8. Gress DR, Smith WS, Dowd CF, Van Halbach V, Finley RJ, Higashida RT. Angioplasty for intracranial symptomatic vertebrobasilar ischemia. Neurosurgery 2002;51:23-27; discussion 27-29.

9. Gupta $R$, Schumacher HC, Mangla S, Meyers PM, Duong $H$, Khandji $A G$, et al. Urgent endovascular revascularization for symptomatic intracranial atherosclerotic stenosis. Neurology 2003;61:1729-1735.

10. Marks MP, Wojak JC, Al-Ali F, Jayaraman M, Marcellus $M L$, Connors JJ, et al. Angioplasty for symptomatic intracranial stenosis: clinical outcome. Stroke 2006;37:1016-1020.

11. Jiang WJ, Wang YJ, Du B, Wang SX, Wang GH, Jin $M$, et al. Stenting of symptomatic M1 stenosis of middle cerebral artery: an initial experience of 40 patients. Stroke 2004;35: 1375-1380.

12. de Rochemont Rdu M, Turowski B, Buchkremer M, Sitzer M, Zanella FE, Berkefeld J. Recurrent symptomatic high-grade intracranial stenoses: safety and efficacy of undersized stents--initial experience. Radiology 2004;231:45-49.

13. Kim JK, Ahn JY, Lee BH, Chung YS, Chung SS, Kim OJ, et al. Elective stenting for symptomatic middle cerebral artery stenosis presenting as transient ischaemic deficits or stroke attacks: short term arteriographical and clinical outcome. J Neurol Neurosurg Psychiatry 2004;75:847-851.

14. SSYLVIA Study Investigators. Stenting of Symptomatic Atherosclerotic Lesions in the Vertebral or Intracranial Arteries (SSYLVIA): study results. Stroke 2004;35:1388-1392.

15. Bose A, Hartmann M, Henkes H, Liu HM, Teng MM, Szikora I, et al. A novel, self-expanding, nitinol stent in medically refractory intracranial atherosclerotic stenoses: the Wingspan study. Stroke 2007;38:1531-1537.

16. Zaidat 00, Klucznik R, Alexander MJ, Chaloupka J, Lutsep $H$, Barnwell S, et al. The NIH registry on use of the Wingspan stent for symptomatic 70-99\% intracranial arterial stenosis. Neurology 2008;70:1518-1524.

17. Nahab F, Lynn MJ, Kasner SE, Alexander MJ, Klucznik R, Zaidat 00, et al. Risk factors associated with major cerebrovascular complications after intracranial stenting. Neurology 2009;72:2014-2019.
18. Fiorella D, Derdeyn CP, Lynn MJ, Barnwell SL, Hoh BL, Levy El, et al. Detailed analysis of periprocedural strokes in patients undergoing intracranial stenting in Stenting and Aggressive Medical Management for Preventing Recurrent Stroke in Intracranial Stenosis (SAMMPRIS). Stroke 2012;43:2682-2688.

19. Chimowitz MI, Lynn MJ, Derdeyn CP, Turan TN, Fiorella D, Lane $B F$, et al. Stenting versus aggressive medical therapy for intracranial arterial stenosis. N Engl J Med 2011;365:9931003.

20. Zaidat O0, Fitzsimmons BF, Woodward BK, Wang Z, KillerOberpfalzer $M$, Wakhloo $A$, et al. Effect of a balloon-expandable intracranial stent vs medical therapy on risk of stroke in patients with symptomatic intracranial stenosis: the VISSIT randomized clinical trial. JAMA 2015;313:1240-1248.

21. Chimowitz MI, Lynn MJ, Turan $T N$, Fiorella $D$, Lane BF, Janis $\mathrm{S}$, et al. Design of the stenting and aggressive medical management for preventing recurrent stroke in intracranial stenosis trial. J Stroke Cerebrovasc Dis 2011;20:357-368.

22. Derdeyn CP, Chimowitz MI, Lynn MJ, Fiorella D, Turan TN, Janis LS, et al. Aggressive medical treatment with or without stenting in high-risk patients with intracranial artery stenosis (SAMMPRIS): the final results of a randomised trial. Lancet 2014;383:333-341.

23. Lutsep $H L$, Lynn MJ, Cotsonis GA, Derdeyn CP, Turan TN, Fiorella $D$, et al. Does the stenting versus aggressive medical therapy trial support stenting for subgroups with intracranial stenosis? Stroke 2015;46:3282-3284.

24. Fiorella D, Levy El, Turk AS, Albuquerque FC, Niemann DB, Aagaard-Kienitz $B$, et al. US multicenter experience with the Wingspan stent system for the treatment of intracranial atheromatous disease: periprocedural results. Stroke 2007;38: 881-887.

25. Miao Z, Zhang Y, Shuai J, Jiang C, Zhu Q, Chen K, et al. Thirty-day outcome of a multicenter registry study of stenting for symptomatic intracranial artery stenosis in China. Stroke 2015;46:2822-2829.

26. Suri MF, Johnston SC. Epidemiology of intracranial stenosis. J Neuroimaging 2009;19 Suppl 1:11S-16S

27. Derdeyn CP, Fiorella D, Lynn MJ, Barnwell SL, Zaidat 00, Meyers PM, et al. Impact of operator and site experience on outcomes after angioplasty and stenting in the SAMMPRIS trial. J Neurointerv Surg 2013;5:528-533.

28. Niu JW, Gao S, Cui LY, Peng B, Zhu YC, Ni J, et al. Intracranial atherosclerosis in Chinese young adult stroke patients. $J$ Stroke Cerebrovasc Dis 2014;23:1519-1523.

29. Ssi-Yan-Kai G, Nasr N, Faury A, Catalaa I, Cognard C, Larrue $V$, et al. Intracranial artery stenosis or occlusion predicts ischemic recurrence after transient ischemic attack. AJNR 
Am J Neuroradiol 2013;34:185-190.

30. Waters MF, Hoh BL, Lynn MJ, Kwon HM, Turan TN, Derdeyn $\mathrm{CP}$, et al. Factors associated with recurrent ischemic stroke in the medical group of the SAMMPRIS trial. JAMA Neurol 2016;73:308-315.

31. Suh DC, Kim JK, Choi JW, Choi BS, Pyun HW, Choi YJ, et al. Intracranial stenting of severe symptomatic intracranial stenosis: results of 100 consecutive patients. AJNR Am J Neuroradiol 2008;29:781-785.

32. Derdeyn CP, Fiorella D, Lynn MJ, Rumboldt Z, Cloft HJ, Gibson $D$, et al. Mechanisms of stroke after intracranial angioplasty and stenting in the SAMMPRIS trial. Neurosurgery 2013;72:777-795; discussion 795.

33. Chaudhry SA, Watanabe M, Qureshi Al. The new standard for performance of intracranial angioplasty and stent placement after Stenting versus Aggressive Medical Therapy for Intracranial Arterial Stenosis (SAMMPRIS) trial. AJNR Am J Neuroradiol 2011;32:E214.

34. Levy El, Turk AS, Albuquerque FC, Niemann DB, Aagaard-Kienitz $B$, Pride $L$, et al. Wingspan in-stent restenosis and thrombosis: incidence, clinical presentation, and management. Neurosurgery 2007;61:644-650; discussion 650-651.

35. Park S, Lee DG, Chung WJ, Lee DH, Suh DC. Long-term outcomes of drug-eluting stents in symptomatic intracranial stenosis. Neurointervention 2013;8:9-14.

36. Qureshi Al, Kirmani JF, Hussein HM, Harris-Lane P, Divani AA, Suri MF, et al. Early and intermediate-term outcomes with drug-eluting stents in high-risk patients with symptomatic intracranial stenosis. Neurosurgery 2006;59:1044-1051; discussion 1051.

37. Abou-Chebl A, Bashir Q, Yadav JS. Drug-eluting stents for the treatment of intracranial atherosclerosis: initial experience and midterm angiographic follow-up. Stroke 2005; 36:e165-e168.

38. Gupta R, Al-Ali F, Thomas AJ, Horowitz MB, Barrow T, Vora
NA, et al. Safety, feasibility, and short-term follow-up of drug-eluting stent placement in the intracranial and extracranial circulation. Stroke 2006;37:2562-2566.

39. Lopez-Cancio E, Matheus MG, Romano JG, Liebeskind DS, Prabhakaran S, Turan TN, et al. Infarct patterns, collaterals and likely causative mechanisms of stroke in symptomatic intracranial atherosclerosis. Cerebrovasc Dis 2014;37:417-422.

40. Liebeskind DS, Cotsonis GA, Saver JL, Lynn MJ, Turan TN, Cloft $\mathrm{HJ}$, et al. Collaterals dramatically alter stroke risk in intracranial atherosclerosis. Ann Neurol 2011;69:963-974.

41. Mazighi M, Tanasescu R, Ducrocq X, Vicaut E, Bracard S, Houdart $E_{1}$ et al. Prospective study of symptomatic atherothrombotic intracranial stenoses: the GESICA study. Neurology 2006;66:1187-1191.

42. Amin-Hanjani S, Pandey DK, Rose-Finnell L, Du X, Richardson $D$, Thulborn $K R$, et al. Effect of hemodynamics on stroke risk in symptomatic atherosclerotic vertebrobasilar occlusive disease. JAMA Neurol 2016;73:178-185.

43. Cui XP, Lin M, Mu JS, Ye JX, He WQ, Fu ML, et al. Angioplasty and stenting for patients with symptomatic intracranial atherosclerosis: study protocol of a randomised controlled trial. BMJ Open 2016;6:e012175.

44. Rassaf T, Totzeck M, Hendgen-Cotta UB, Shiva S, Heusch G, Kelm M. Circulating nitrite contributes to cardioprotection by remote ischemic preconditioning. Circ Res 2014;114:1601-1610.

45. Liu C, Wajih N, Liu X, Basu S, Janes J, Marvel M, et al. Mechanisms of human erythrocytic bioactivation of nitrite. J Biol Chem 2015;290:1281-1294.

46. Meng R, Asmaro K, Meng L, Liu Y, Ma C, Xi C, et al. Upper limb ischemic preconditioning prevents recurrent stroke in intracranial arterial stenosis. Neurology 2012;79:1853-1861.

47. Meng R, Ding Y, Asmaro K, Brogan D, Meng L, Sui M, et al. Ischemic conditioning is safe and effective for octo- and nonagenarians in stroke prevention and treatment. Neurotherapeutics 2015;12:667-677. 